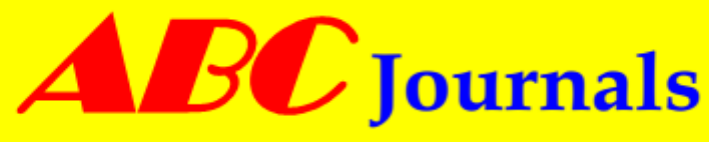

A new domain in research publishing

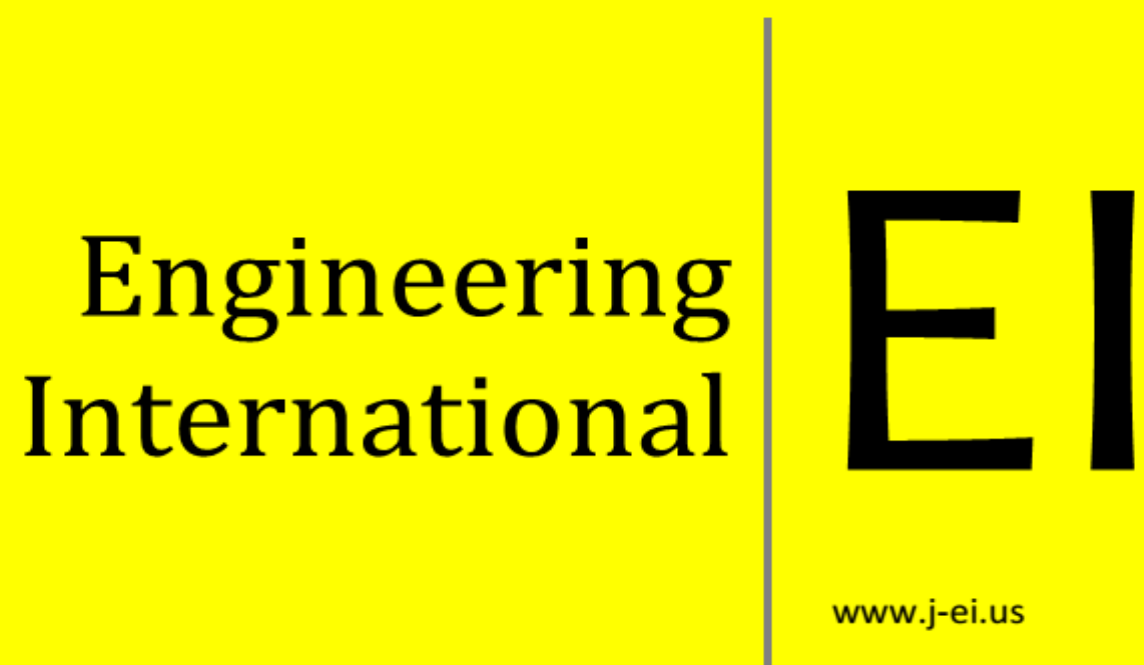

Asian Business Consortium 


\title{
Study on MHD Boundary Layer Flow of Combined Heat and Mass Transfer Over a Moving Inclined Plate in a Porous Medium With Suction and Viscous Dissipation in Presence of Hall Effect
}

\section{Mohammad Ali, \& Mohammad Shah Alam}

Assistant Professor, Department of Mathematics, Chittagong University of Engineering and Technology, Chittagong, Bangladesh

\begin{abstract}
The Hall effects on the steady MHD boundary layer flow of an incompressible fluid of combined heat and mass transfer over a moving inclined plate in a porous media with suction and viscous dissipation has studied. An external magnetic field is applied perpendicular to the surface and the fluid motion is subjected to a uniform suction and injection. A closed form solutions of the equations governing the flow are obtained for the velocity, secondary velocity, and temperature and concentration profiles. The dimensionless governing equations are solved using $\mathrm{R}$ $\mathrm{K}$ method along with shooting technique. The velocities, temperature and concentration profiles are presented graphically for different values of governing flow parameters. The results presented graphically illustrate that primary velocity field decrease due to increase of magnetic parameter, angle of inclination, permeability parameter and suction parameter while secondary velocity also decrease for magnetic parameter, Hall parameter and permeability parameter .Other parameters increase the velocities of the fluid flow. Temperature field increases in the presence of Magnetic parameter, Grashof number, Modified Grashof number and permeability parameter and decreases for Prandlt number and suction parameter. Also, concentration profiles decreases for increasing the values of magnetic parameter, Hall parameter, Schmid number and suction parameter but there is no effect on concentration of the remaining parameters. Also the skin friction coefficient, the local Nusselt number and the local Sherwood number are presented in Tables 1-3.
\end{abstract}

Keywords: Hall Effect, MHD, Porous media, Suction, Dissipation

\section{INTRODUCTION}

The study of boundary layer flow heat and mass transfer over an inclined plate has generated much interest from astrophysical, renewable energy systems and also hypersonic aerodynamics researchers for a number of decades. MHD flow problems have become important in industrial manufacturing processes such as plasma studies, chemical 
engineering, electrochemistry, polymer processing, petroleum industries, Magnetohydrodynamics power generator cooling of clear reactors, boundary layer control in aerodynamics. Several researchers have studied the effects of magnetic field on mixed, natural and force convection heat and mass transfer problems. This problem has also an important bearing on metallurgy where magneto-hydrodynamic (MHD) techniques have recently been used. The study of effects of porous boundaries on heat and mass transfer is important because of its many engineering applications in the field of chemical and geophysical sciences. Permeable porous plates are used in the filtration processes and also for a heated body to keep its temperature constant and to make the heat in solution of the surface more effective. Previous studies deals with the studies concerning non-Newtonian flows and heat transfer in the absence of magnetic fields, but presently we find several industrial applications such as polymer technology and metallurgy (Chakrabarti and Gupta 1979), where the magnetic field is applied in the viscoelastic fluid flow. (Sarpakaya1961) was mostly first researcher to investigate MHD flows of non-Newtonian fluids, (Andersson1992) investigated the flow problem of electrically conducting viscoelastic fluid past a flat and impermeable elastic sheet and later his work is extended by many authors (Prasadet al 2010; Abel and Mahesha 2008; Seddeek 2007; Joshi et al 2001; Veenaet al 2004; Hasimoto1957) discussed the boundary layer growth on a heat plate with suction or injection. (Mishra and Dash 1974) studied free convection of non- permeable fluid between parallel walls. (Vajravalu1979) studied natural convection at a heated semiinfinite vertical plate with internal heat generation. (Pop and Soundalgekar 1980) investigated free convection flow past on accelerated infinite plate. (Singh 1983) analyzed the MHD free convective flow past an accelerated vertical porous plate by finite difference method. (Rapits et al. 1987) studied the unsteady free convective flow through a porous medium adjacent to a semi-infinite vertical plate using finite difference scheme.(Singh and Dikshit1988) studied hydromagnetic flow past a continuously moving semi-infinite plate at large suction. (Singh and Soundalgekar 1990) investigated of transient free convection in cold water past an infinite vertical porous plate. (Sattar 1994) discussed free convection and mass transfer flow through a porous medium past an infinite vertical porous plate with time dependent temperature and concentration. (Acharya et al. 1995) investigated the effect of chemical and thermal diffusion with Hall current on unsteady hydromagnetic flow near an infinite vertical porous plate. (Dash and Das 1999) analyzed the effect of Hall current MHD free convection flow along an accelerated porous heated plate with mass transfer and internal heat generation. (Soundalgekar et al. 1974) studied transient free convection flow of a viscous dissipative fluid past a semi-infinite vertical plate. (Cookey et al. 2003) studied the influence of viscous dissipation and radiation on unsteady MHD free convection flow past an infinite heated vertical plate in a porous medium with time dependent suction.(Sharma and Mishra 2002) analyzed the effect of mass transfer in unsteady MHD flow and heat transfer past an infinite porous vertical moving plate. (Panda et al. 2003) discussed unsteady free convective flow and mass transfer of a rotating elastic viscous liquid through porous media past a vertical porous plate.(Das et al 2006) studied unsteady free convection and mass transfer boundary layer flow past an accelerated infinite vertical porous plate with suction. (Sharma and Singh 2008) investigated unsteady MHD free convective flow and heat transfer along a vertical porous plate with variable suction and internal heat generation. The aim of the paper is to investigate steady MHD boundary layer flow of an incompressible fluid of combined heat and mass transfer over a moving inclined plate in a porous media with suction and viscous dissipation in presence of Hall current. The governing equations are solved both analytically and 
numerically using Runge-kutta forth-fifth order method along with shooting technique. The effect of the parameters on the velocity, temperature and the concentration distributions of the flow filed are discussed and shown through graphs. The results are analysed for various physical parameters such as of the porous medium, magnetic field, Local thermal Grashof number, Local solutal Grashof number, Schmidt number, Prandtl number, Ecket number, Hall parameter on the flow, heat and mass transfer characteristics.

\section{Mathematical Formulation of the Problem}

Let us consider a two dimensional steady laminar MHD viscous incompressible electrically conducting fluid along an inclined plate with an acute angle $\gamma$.X-direction is taken along the leading edge of the inclined plate and $\mathrm{Y}$ is normal to it and extends parallel to $\mathrm{X}$-axis. A magnetic field of strength $B_{0}$ is introduced to the normal to the direction to the flow. The uniform plate temperature $\mathrm{T}_{\mathrm{w}}\left(>\mathrm{T}_{\infty}\right)$, where $\mathrm{T}_{\infty}$ is the temperature of the fluid far away from the plate. Let $\mathrm{u}, \mathrm{v}$ and $\mathrm{w}$ be the velocity components along the $\mathrm{x}$ and $\mathrm{y}$ axis and secondary velocity component along the $\mathrm{z}$ axis respectively in the boundary layer region. The sketch of the physical configuration and coordinate system are shown in Figure-1.

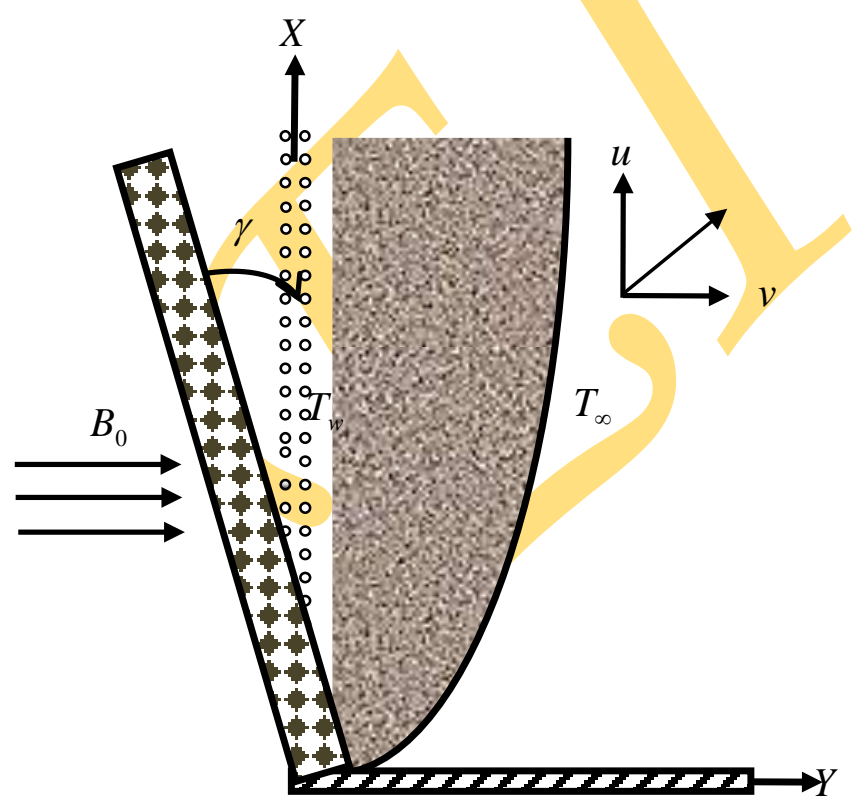

Figure-1 Physical configuration and coordinate system.

Under the above assumptions and usual boundary layer approximation, the dimensional governing equations of continuity, momentum, concentration and energy under the influence of externally imposed magnetic field are:

Equation of continuity:

$$
\frac{\partial u}{\partial x}+\frac{\partial v}{\partial y}=0
$$

Momentum equation: 
Engineering International, Volume 2, No 1 (2014)

$$
\begin{aligned}
& \mathrm{u} \frac{\partial \mathrm{u}}{\partial \mathrm{x}}+\mathrm{v} \frac{\partial \mathrm{u}}{\partial \mathrm{y}}=v \frac{\partial^{2} \mathrm{u}}{\partial \mathrm{y}^{2}}+\mathrm{g} \beta\left(\mathrm{T}-\mathrm{T}_{\infty}\right) \cos \gamma+ \\
& \mathrm{g} \beta^{*}\left(\mathrm{C}-\mathrm{C}_{\infty}\right) \cos \gamma-\frac{\sigma \mathrm{B}_{0}^{2}}{\rho\left(1+\mathrm{m}^{2}\right)}(\mathrm{u}+\mathrm{mw})-\frac{v}{\mathrm{k}^{*}} u \\
& \mathrm{u} \frac{\partial \mathrm{w}}{\partial \mathrm{x}}+\mathrm{v} \frac{\partial \mathrm{w}}{\partial \mathrm{y}}=v \frac{\partial^{2} \mathrm{w}}{\partial \mathrm{y}^{2}}+\frac{\sigma \mathrm{B}_{0}^{2}}{\rho\left(1+\mathrm{m}^{2}\right)}(\mathrm{mu}-\mathrm{w})-\frac{v}{\mathrm{k}^{*}} \mathrm{~W}
\end{aligned}
$$

Energy Equation:

$$
u \frac{\partial T}{\partial x}+v \frac{\partial T}{\partial y}=\alpha \frac{\partial^{2} T}{\partial y^{2}}+\frac{v}{c_{p}}\left[\left(\frac{\partial u}{\partial y}\right)^{2}+\left(\frac{\partial w}{\partial y}\right)^{2}\right], \alpha=\frac{k}{\rho c_{p}}
$$

Concentration Equation:

$$
\mathrm{u} \frac{\partial \mathrm{c}}{\partial \mathrm{x}}+\mathrm{v} \frac{\partial \mathrm{c}}{\partial \mathrm{y}}=\mathrm{D} \frac{\partial^{2} \mathrm{c}}{\partial \mathrm{y}^{2}}
$$

Boundary conditions are :

$$
\begin{aligned}
& \mathrm{u}=\mathrm{Ax}, \mathrm{v}=\mathrm{V}, \mathrm{w}=0, \mathrm{~T}=\mathrm{T}_{\mathrm{w}}=\mathrm{T}_{\mathrm{x}}+\mathrm{ax}, \\
& \mathrm{C}=\mathrm{C}_{\mathrm{w}}=\mathrm{c}_{\mathrm{x}}+\mathrm{bx} \quad \text { at } \mathrm{y}=0 \\
& \mathrm{u}=0, \mathrm{w}=0, \mathrm{~T}=\mathrm{T}_{\infty}, \mathrm{C}=\mathrm{C}_{\infty} \text { as } \mathrm{y} \rightarrow \infty
\end{aligned}
$$

To convert the governing equations into a set of similarity equations, we introduce the following similarity transformation:

$$
\begin{aligned}
& \mathrm{w}=\operatorname{Ag}_{0}(\eta), \eta=y \sqrt{\frac{\mathrm{A}}{v \mathrm{x}}}, \psi=\sqrt{v \operatorname{Ax} f}(\eta), \mathrm{k}^{*}=\frac{v \mathrm{x}}{\mathrm{Ak}} \\
& \theta(\eta)=\frac{\mathrm{T}-\mathrm{T}_{\infty}}{\mathrm{T}_{\mathrm{w}}-\mathrm{T}_{\infty}}, \varphi(\eta)=\frac{\mathrm{C}-\mathrm{C}_{\infty}}{\mathrm{C}_{\mathrm{w}}-\mathrm{C}_{\infty}}, \mathrm{F}_{\mathrm{w}}=\frac{2 \mathrm{~V}}{\sqrt{v \mathrm{~A}}}
\end{aligned}
$$

From the above transformations, the non-dimensional, nonlinear and coupled ordinary differential equations are obtained

$$
\begin{gathered}
\mathrm{f}^{\prime \prime \prime}+\frac{1}{2} \mathrm{ff}^{\prime}+\mathrm{G}_{\mathrm{r}} \theta \cos \gamma+\mathrm{G}_{\mathrm{c}} \varphi \cos \gamma- \\
\frac{\mathrm{M}^{2}}{1+\mathrm{m}^{2}} \mathrm{f}^{\prime}-\mathrm{Mg}_{0}-\mathrm{Kf}=0 \\
\mathrm{~g}_{0}^{\prime \prime}+\mathrm{fg}_{0}^{\prime}-\frac{2 \mathrm{M}}{1+\mathrm{m}^{2}} \mathrm{~g}_{0}-\frac{2 \mathrm{Mm}}{1+\mathrm{m}^{2}} \mathrm{f}^{\prime}-2 \mathrm{Kf}^{\prime}=0 \\
\theta^{\prime \prime}+\frac{1}{2} \mathrm{P}_{\mathrm{r}} \mathrm{f}^{\prime}+\mathrm{E}_{\mathrm{c}}\left[\mathrm{f}^{\prime \prime 2}+\mathrm{g}_{0}^{2}\right]=0 \\
\varphi^{\prime \prime}+\frac{1}{2} \mathrm{~S}_{\mathrm{c}} \mathrm{f} \varphi=0
\end{gathered}
$$

The transform boundary conditions:

$\mathrm{f}=-\mathrm{F}_{\mathrm{w}}, \mathrm{g}_{0}=0, \mathrm{f}^{\prime}=1, \theta=\varphi=1$ at $\eta=0$

$\mathrm{f}=\mathrm{f}^{\prime}=\mathrm{g}_{0}=\theta=\varphi=0$ as $\eta \rightarrow \infty$ 


\section{Results AND Discussion}

In order to get a physical insight of the problem, a representative set of numerical results are shown graphically in Figure-2 to Figure-27 to illustrate the influence of physical parameters viz., the suction parameter $\mathrm{F}_{\mathrm{w}}$, magnetic parameter $\mathrm{M}$, Hall parameter $\mathrm{m}$, thermal conductivity $\mathrm{K}$, buoyancy parameter $\mathrm{Gr}_{\mathrm{r}} \& \mathrm{G}_{\mathrm{c}}$, Eckert number $\mathrm{E}_{\mathrm{c}}$, Schmidt number $\mathrm{S}_{\mathrm{c}}$, Prandlt Number $\mathrm{P}_{\mathrm{r}}$ and inclination parameter $\gamma$ on the velocity , secondary velocity, temperature and concentration profiles. Figure-2 to Figure- 9 shows the effects of various parameters on dimensionless primary velocity profile. The effects of $M$ and $m$ on the primary and secondary velocity profiles are shown in Fig. 2, Fig.10, Fig.3 and Fig.11. It can be clearly seen that an increase in the magnetic parameter decreases the primary velocity and also the secondary velocity. This result agrees with the expectations, since the magnetic field exerts a retarding effect on the free convective flow. This field may control the flow characteristics, an increase in $M$ results in thinning of the boundary layer. The effect of the Hall parameter has a minor increasing effect on the primary velocity, whereas the major decreasing effect on the secondary velocity. Fig.17, Fig.20, \& Fig.21 depicts the temperature and concentration profiles for $\mathrm{M}$ and $\mathrm{m}$. From these figure it is observed that temperature increases for increasing values of $\mathrm{M}$ but negligible decreasing effect on concentration for increasing values $\mathrm{M}$ and $\mathrm{m}$. Figure- 4 shows the dimensionless velocity profile for various values of $\gamma$. It is observed that for the effects of $\gamma$ the velocity decreases. From Fig. 5 to Fig. 7 it is observed that the velocity profile is increased for the effect of $\mathrm{Pr}_{\mathrm{r}}$ $\mathrm{Gr}_{\mathrm{r}}$, and $\mathrm{G}_{\mathrm{c}}$ that is the flow accelerated corresponding to an increase of these parameters but velocity is decreased for various values of $\mathrm{K}$ and $\mathrm{F}_{\mathrm{w}}$ which shown in Fig.8 and Fig.9. On the other hand from Fig.12 and Fig.13 it is seen that, as expected secondary velocity increases with the increasing values of the parameters $G_{r}$ and $G_{c}$ that is these parameters acts as an influence forces. As a result the boundary layer thickness increases but Fig.14 shows the dimensionless secondary velocity profiles for different values of $\mathrm{K}$. It is seen that, as expected secondary velocity decreases with an increase in K. Fig.15 illustrates the influence of physical parameters $\mathrm{P}_{\mathrm{r}}$ on the temperature profile. It is observed that in air and salt water the variation of temperature is slower than fresh water for the effect of $\mathrm{P}_{\mathrm{r}}$. From Fig.28 it is seen that temperature is decreased in the increasing values of $F_{w}$. From Fig.16 and Fig.18 it is observed that temperature profile increases for increasing values of Gr and G. From Fig.19 it is interesting to note that the temperature profile is decreased for $\mathrm{K} \leq 2$ but when $\mathrm{K}^{\geq 3}$ then it is increased. Fig.22 to Fig.25 it is observed that there is no effect on concentration profile of the parameters Gr, Gc, Pr and K. From Fig.26 and Fig.27 it is seen that the concentration is decreased for the increasing values of $S_{c}$ and $F_{w}$. Tables 1-3 exhibit the behaviour of $\mathrm{f}^{\prime \prime}(0),-\theta^{\prime}(0)$, and $-\varphi^{\prime}(0)$, for various values of magnetic parameter, Hall parameter, Pr and tl number, angle of inclination, Permeability parameter, Grashof Number, Modified Grashof number and Suction/injection parameter. From Table1 , it is observed that $\mathrm{f}^{\prime \prime}(0)$ is decreased for various values of $\mathrm{M}, \gamma, \mathrm{K}$, and $\mathrm{F}_{\mathrm{w}}$ and increased for increasing values of $m, P_{r}, G r, G_{c}$ and $F_{w}$. From Table- 2, it is observed that $\theta^{\prime}(0)$, is decreased with the increasing values of $K, P_{r}$ and $F_{w}$ but increased for increasing values of 
M, Gr, Gc and K. From Table- 3, we see that $\varphi^{\prime}(0)$, is decreased with the increase of M, m, Sc and $F_{w}$ and there is no effect for $G_{r}, G_{c}, P_{r}$ and $K$.

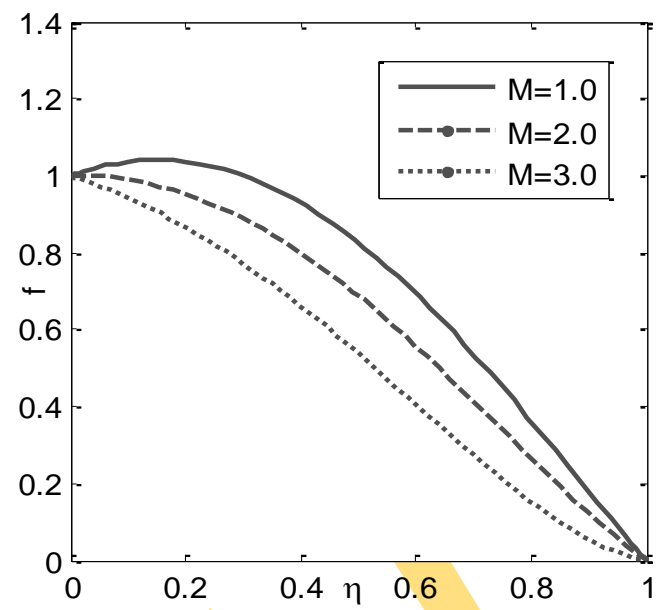

Fig.2 Primary velocity profile for various values of $M$ and $m=0.2, \gamma=30^{\circ}, P_{r}=0.71, G_{r}=G_{c}$

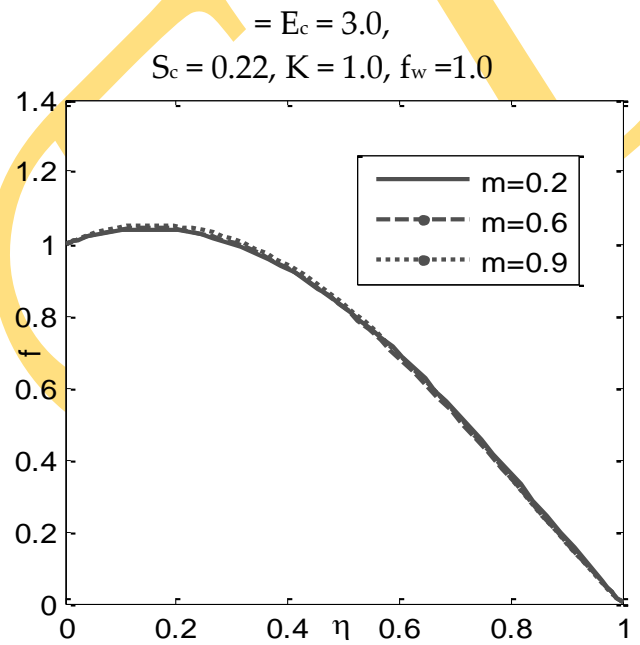

Fig.3 Primary velocity profile for various values of $\mathrm{m}$ and $\mathrm{M}=1.0, \gamma=30^{\circ}, \mathrm{P}_{\mathrm{r}}=0.71, \mathrm{G}_{\mathrm{r}}=\mathrm{G}_{\mathrm{c}}$

$$
\begin{aligned}
=E_{c} & =3.0, \\
S_{c}=0.22, K & =1.0, f_{w}=1.0
\end{aligned}
$$


Engineering International, Volume 2, No 1 (2014)

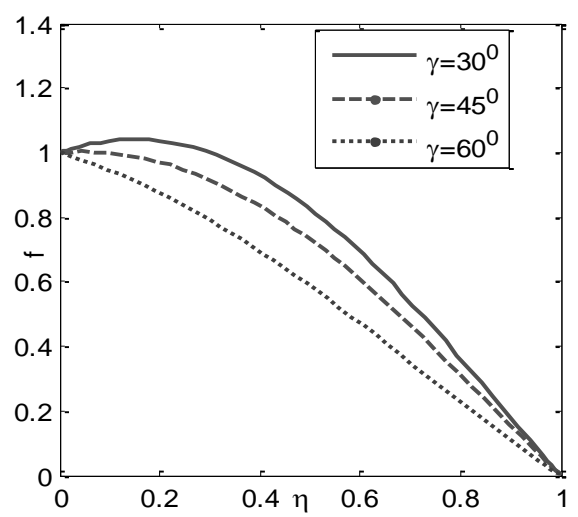

Fig.4 Primary velocity profile for various values of $\gamma$ and

$$
\begin{gathered}
\mathrm{M}=1.0, \mathrm{~m}=0.2, \mathrm{Pr}_{\mathrm{r}}=0.71, \mathrm{G}_{\mathrm{r}}=\mathrm{G}_{\mathrm{c}}=\mathrm{E}_{\mathrm{c}}=3.0, \\
\mathrm{~S}_{\mathrm{c}}=0.22, \mathrm{~K}=1.0, \mathrm{f}_{\mathrm{w}}=1.0
\end{gathered}
$$

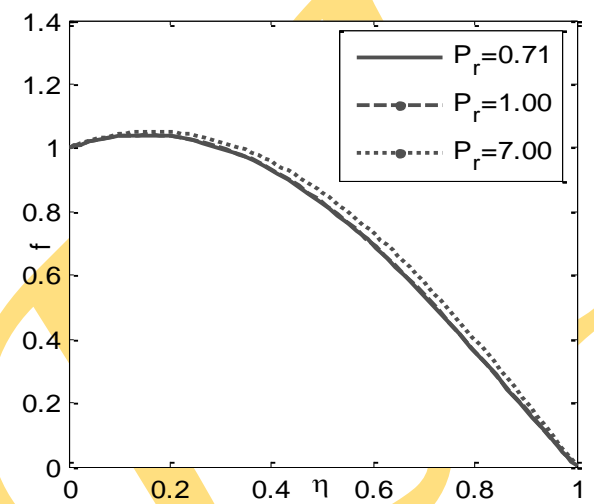

Fig.5 Primary velocity profile for various values of $P_{r}$ and $m=0.2, \gamma=30^{\circ}, M=1.0, G_{r}=G_{c}=$ $\mathrm{E}_{\mathrm{c}}=3.0$,

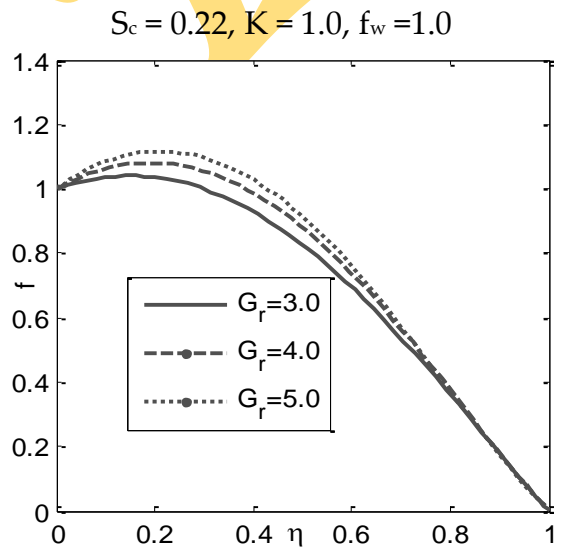

Fig.6 Primary velocity profile for various values of $G_{r}$ and $m=0.2, \gamma=30^{\circ}, M=1.0, P_{r}=G_{c}=$ $\mathrm{E}_{\mathrm{c}}=3.0$,

$$
\mathrm{S}_{\mathrm{c}}=0.22, \mathrm{~K}=1.0, \mathrm{f}_{\mathrm{w}}=1.0
$$


Engineering International, Volume 2, No 1 (2014)

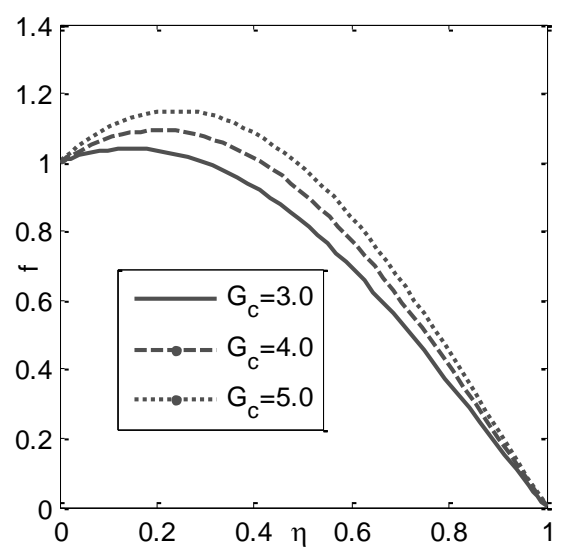

Fig.7 Primary velocity profile for various values of $G_{c}$ and $m=0.2, \gamma=30^{\circ}, M=1.0, P_{r}=G_{r}=$ $\mathrm{E}_{\mathrm{c}}=3.0$,

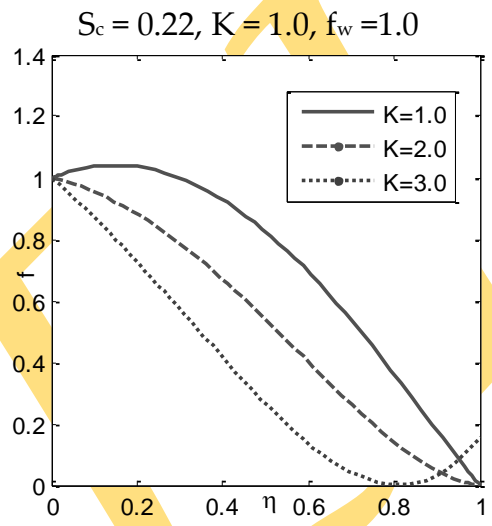

Fig.8 Primary velocity profile for various values of $K$ and $M=1.0, m=0.2, P_{r}=0.71, G_{r}=G_{c}$ $=\mathrm{E}_{\mathrm{c}}=3.0$,

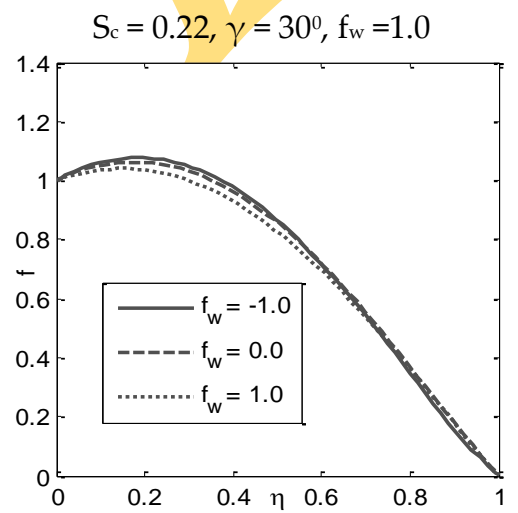

Fig.9 Primary velocity profile for various values of $f_{w}$ and $M=1.0, m=0.2, P_{r}=0.71, G_{r}=G_{c}$

$$
\begin{gathered}
=E_{c}=3.0, \\
S_{c}=0.22, \gamma=30^{\circ}, K=1.0
\end{gathered}
$$


Engineering International, Volume 2, No 1 (2014)

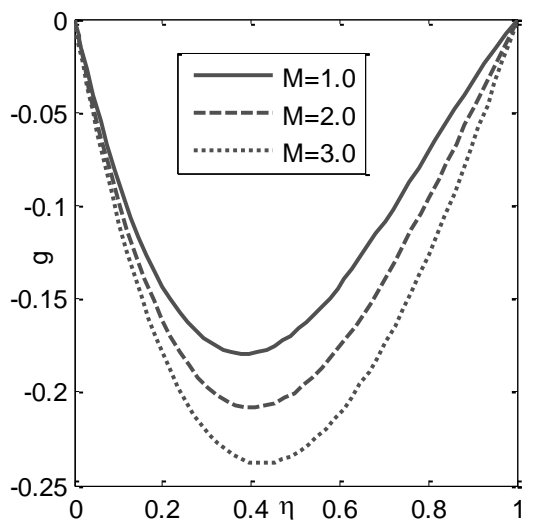

Fig.10 Secondary velocity profile for various values of $\mathrm{M}$ and $\mathrm{m}=0.2, \gamma=30^{\circ}, \mathrm{Pr}_{\mathrm{r}}=0.71, \mathrm{Gr}=$ $\mathrm{G}_{\mathrm{c}}=\mathrm{E}_{\mathrm{c}}=3.0$,

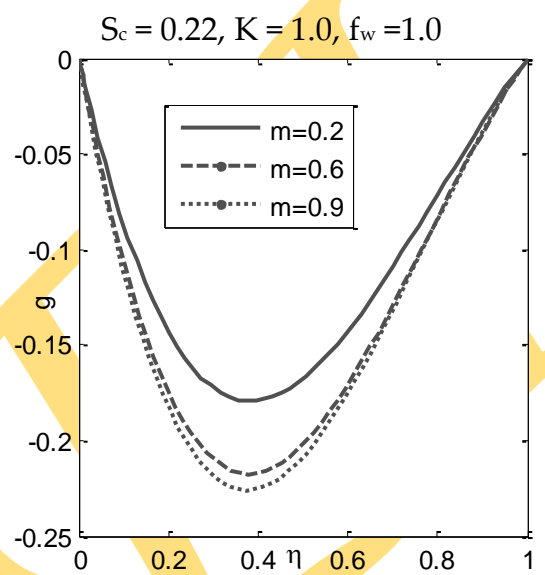

Fig.11 Secondary velocity profile for various values of $\mathrm{m}$ and $\mathrm{M}=1.0, \gamma=30^{\circ}, \mathrm{Pr}_{\mathrm{r}}=0.71, \mathrm{Gr}_{\mathrm{r}}=$ $\mathrm{G}_{\mathrm{c}}=\mathrm{E}_{\mathrm{c}}=3.0$,

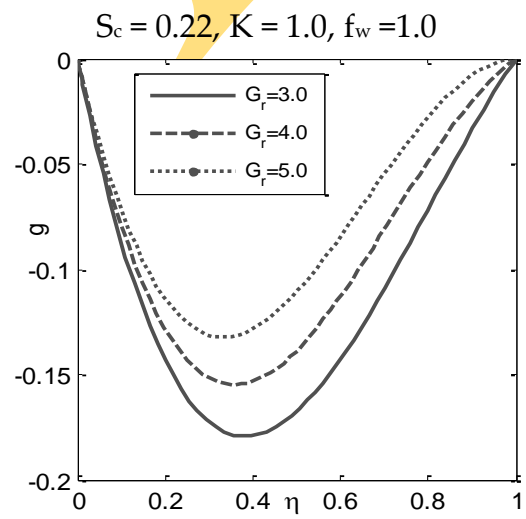

Fig.12 Secondary velocity profile for various values of $G_{r}$ and $m=0.2, \gamma=30^{\circ}, M=1.0, P_{r}=$ $\mathrm{G}_{\mathrm{c}}=\mathrm{E}_{\mathrm{c}}=3.0$,

$\mathrm{S}_{\mathrm{c}}=0.22, \mathrm{~K}=1.0, \mathrm{f}_{\mathrm{w}}=1.0$ 
Engineering International, Volume 2, No 1 (2014)

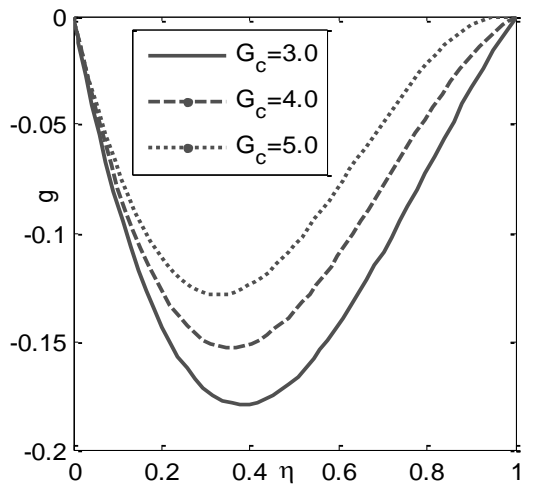

Fig.13 Secondary velocity profile for various values of $G_{c}$ and $m=0.2, \gamma=30^{\circ}, M=1.0, P_{r}=$ $\mathrm{G}_{\mathrm{r}}=\mathrm{E}_{\mathrm{c}}=3.0$,

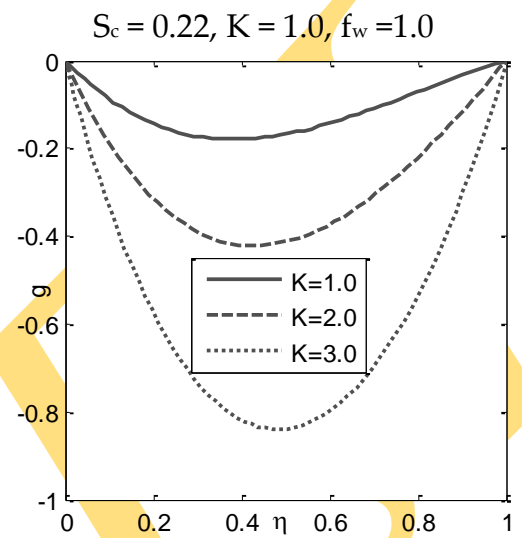

Fig.14 Secondary velocity profile for various values of $\mathrm{K}$ and $\mathrm{M}=1.0, \mathrm{~m}=0.2, \mathrm{P}_{\mathrm{r}}=0.71, \mathrm{G}_{\mathrm{r}}=$ $\mathrm{G}_{\mathrm{c}}=\mathrm{E}_{\mathrm{c}}=3.0$,

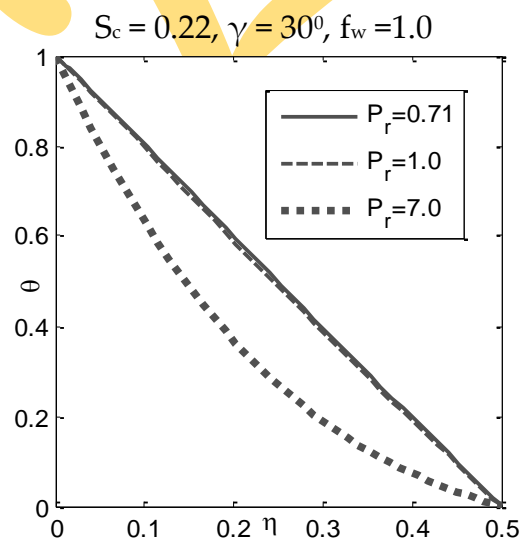

Fig.15 Temperature profile for various values of $P_{r}$ and $m=0.2, \gamma=30^{\circ}, M=1.0, G_{r}=G_{c}=E_{c}$ $=3.0$,

$\mathrm{S}_{\mathrm{c}}=0.22, \mathrm{~K}=1.0, \mathrm{f}_{\mathrm{w}}=1.0$ 
Engineering International, Volume 2, No 1 (2014)

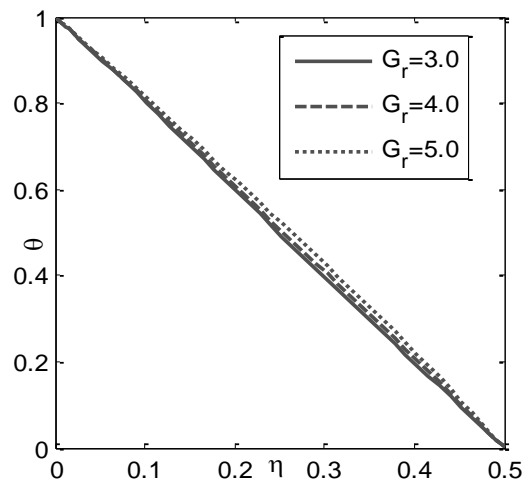

Fig.16 Temperature profile for various values of $G_{r}$ and $m=0.2, \gamma=30^{\circ}, M=1.0, P_{r}=G_{c}=E_{c}$ $=3.0$,

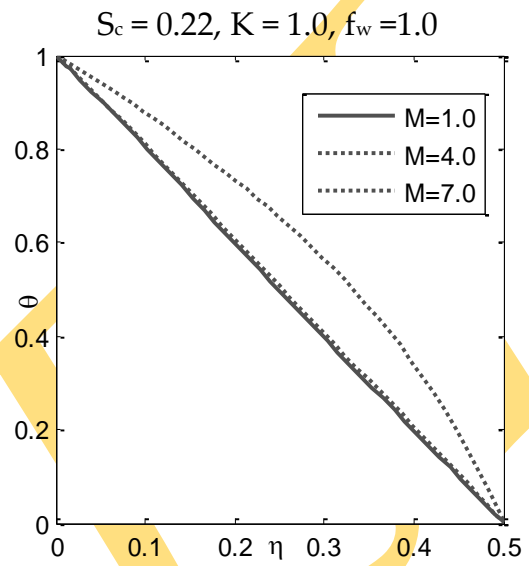

Fig.17 Temperature profile for various values of $\mathrm{M}$ and $\mathrm{m}=0.2, \gamma=30^{0}, \mathrm{P}_{\mathrm{r}}=0.71, \mathrm{G}_{\mathrm{r}}=\mathrm{G}_{\mathrm{c}}=$ $\mathrm{E}_{\mathrm{c}}=3.0$,

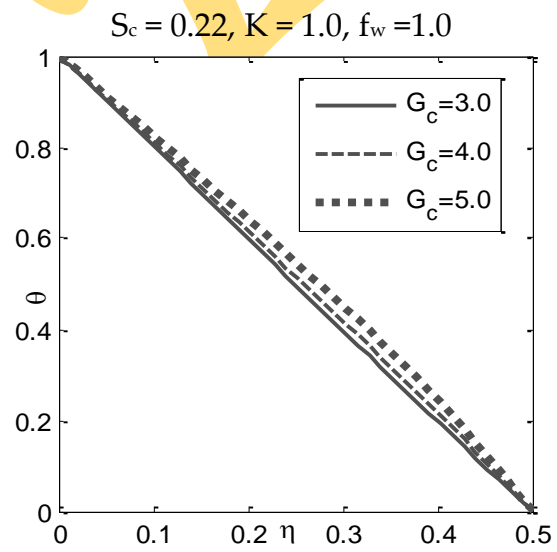

Fig.18 Temperature profile for various values of $G_{c}$ and $m=0.2, \gamma=30^{\circ}, M=1.0, P_{r}=G_{r}=E_{c}$ $=3.0$,

$$
\mathrm{S}_{\mathrm{c}}=0.22, \mathrm{~K}=1.0, \mathrm{f}_{\mathrm{w}}=1.0
$$


Engineering International, Volume 2, No 1 (2014)

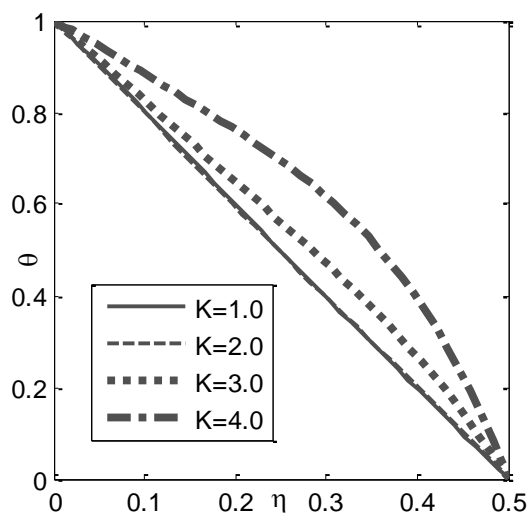

Fig.19 Temperature profile for various values of $\mathrm{K}$ and $\mathrm{M}=1.0, \mathrm{~m}=0.2, \mathrm{P}_{\mathrm{r}}=0.71, \mathrm{G}_{\mathrm{r}}=\mathrm{G}_{\mathrm{c}}=$

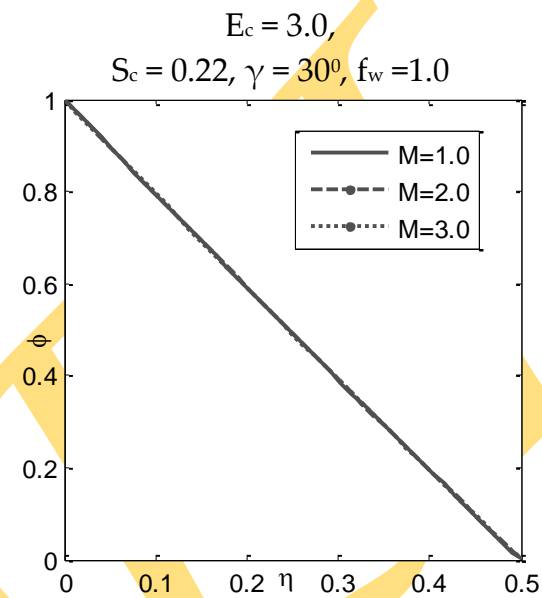

Fig.20 Concentration profile for various values of $\mathrm{M}$ and $\mathrm{m}=0.2, \gamma=30^{0}, \mathrm{P}_{\mathrm{r}}=0.71, \mathrm{G}_{\mathrm{r}}=\mathrm{G}_{\mathrm{c}}=$

$$
\mathrm{E}_{\mathrm{c}}=3.0 \text {, }
$$

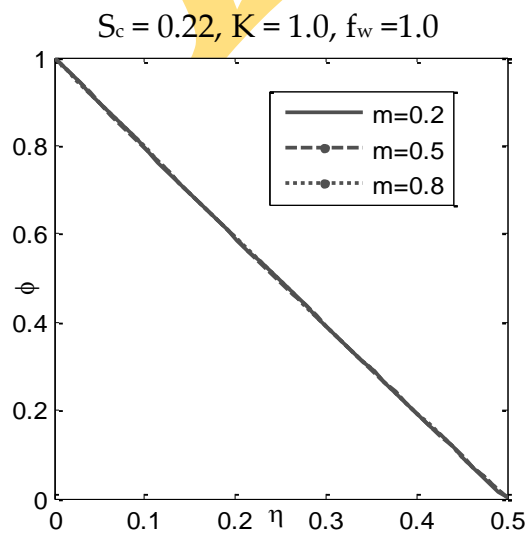

Fig.21 Concentration profile for various values of $\mathrm{m}$ and $\mathrm{M}=1.0, \gamma=30^{0}, \mathrm{Pr}_{\mathrm{r}}=0.71, \mathrm{G}_{\mathrm{r}}=\mathrm{G}_{\mathrm{c}}=$ $\mathrm{E}_{\mathrm{c}}=3.0$,

$$
\mathrm{S}_{\mathrm{c}}=0.22, \mathrm{~K}=1.0, \mathrm{f}_{\mathrm{w}}=1.0
$$


Engineering International, Volume 2, No 1 (2014)

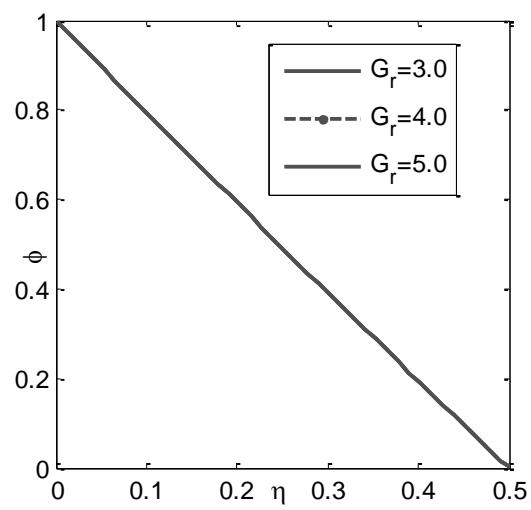

Fig.22 Concentration profile for various values of $G_{r}$ and $m=0.2, \gamma=30^{\circ}, M=1.0, P_{r}=G_{c}=$ $\mathrm{E}_{\mathrm{c}}=3.0$,

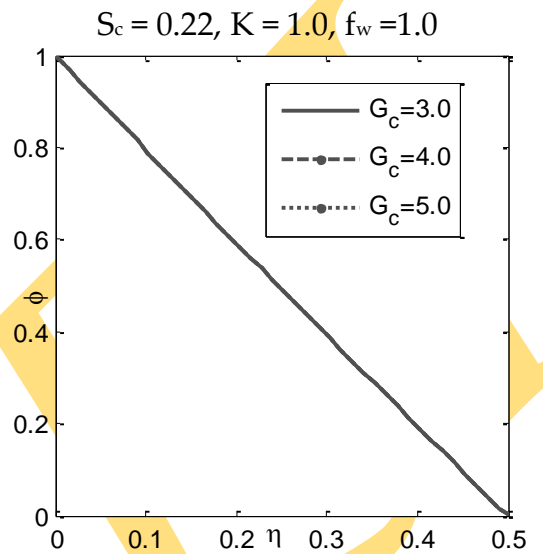

Fig.23 Concentration profile for various values of $G_{c}$ and $m=0.2, \gamma=30^{\circ}, M=1.0, P_{r}=G_{r}=$ $\mathrm{E}_{\mathrm{c}}=3.0$,

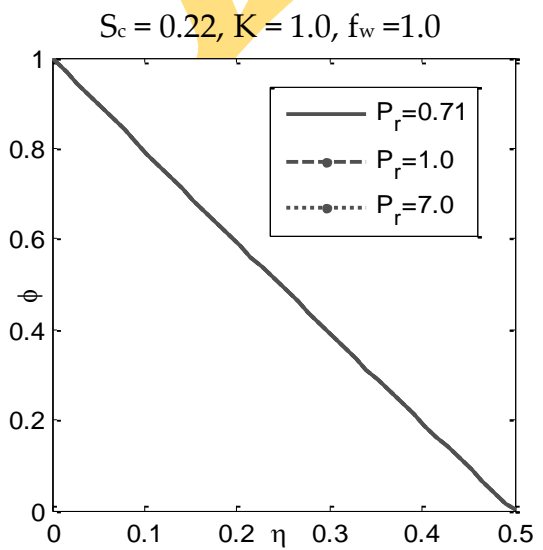

Fig.24 Concentration profile for various values of $P_{r}$ and $m=0.2, \gamma=30^{\circ}, M=1.0, G_{r}=G_{c}=$ $\mathrm{E}_{\mathrm{c}}=3.0$,

$$
\mathrm{S}_{\mathrm{c}}=0.22, \mathrm{~K}=1.0, \mathrm{f}_{\mathrm{w}}=1.0
$$


Engineering International, Volume 2, No 1 (2014)

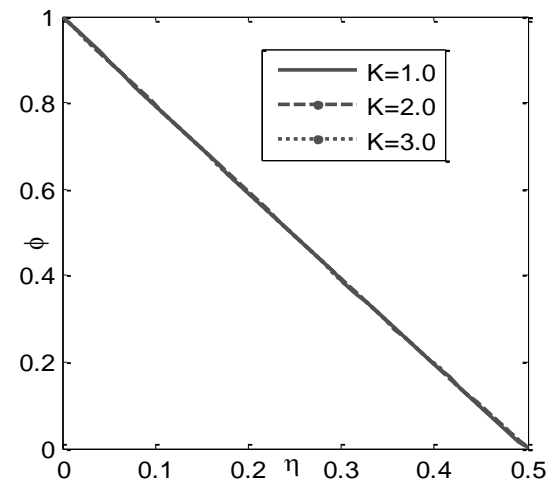

Fig.25 Concentration profile for various values of $\mathrm{K}$ and $\mathrm{M}=1.0, \mathrm{~m}=0.2, \mathrm{P}_{\mathrm{r}}=0.71, \mathrm{G}_{\mathrm{r}}=\mathrm{G}_{\mathrm{c}}=$ $\mathrm{E}_{\mathrm{c}}=3.0$,

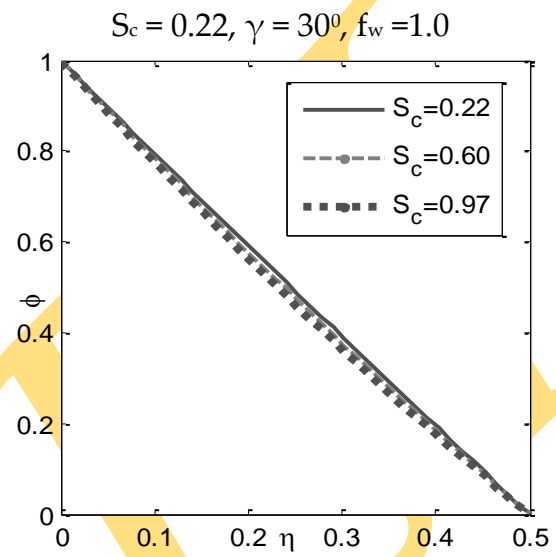

Fig.26 Concentration profile for various values of $S_{c}$ and $m=0.2, \gamma=30^{\circ}, P_{r}=0.71, G_{r}=G_{c}=$ $\mathrm{E}_{\mathrm{c}}=3.0$,

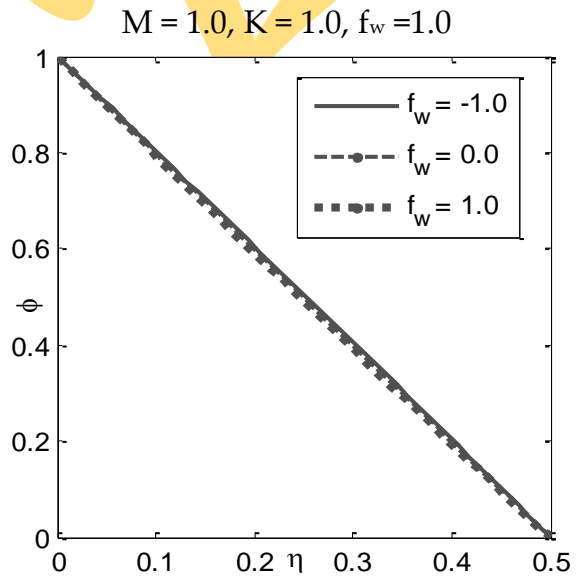

Fig.27 Concentration profile for various values of $\mathrm{f}_{\mathrm{w}}$ and $\mathrm{M}=1.0, \mathrm{~m}=0.2, \mathrm{P}_{\mathrm{r}}=0.71, \mathrm{G}_{\mathrm{r}}=\mathrm{G}_{\mathrm{c}}=$ $\mathrm{E}_{\mathrm{c}}=3.0$,

$$
\mathrm{S}_{\mathrm{c}}=0.22, \gamma=30^{\circ}, \mathrm{K}=1.0
$$




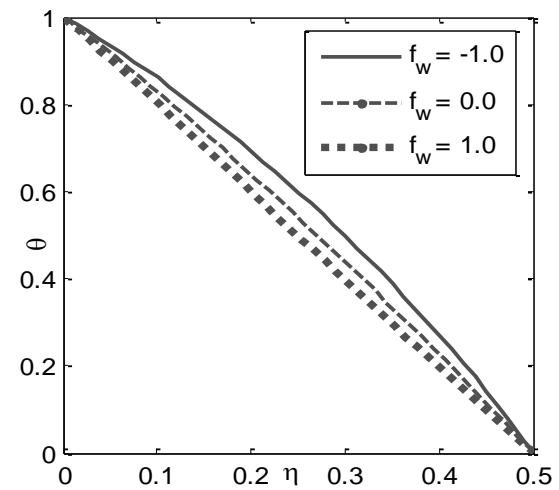

Fig.28 Temperature profile for various values of $\mathrm{f}_{\mathrm{w}}$ and $\mathrm{M}=1.0, \mathrm{~m}=0.2, \mathrm{P}_{\mathrm{r}}=0.71, \mathrm{G}_{\mathrm{r}}=\mathrm{G}_{\mathrm{c}}=$

$$
\begin{gathered}
E_{c}=3.0, \\
S_{c}=0.22, \gamma=30^{\circ}, K=1.0
\end{gathered}
$$

\section{CONCLUSIONS}

The present numerical study has been investigated steady MHD boundary layer flow of an incompressible fluid of combined heat and mass transfer over a moving inclined plate in a porous media with suction and viscous dissipation in presence of Hall current. The shooting method with RK-45 iteration scheme has been implemented to solve the dimensionless velocity, thermal and mass boundary layer equations. From the present study, we arrive at the following significant observations.

- $\quad$ The magnitude of velocity decreases with increasing magnetic parameter causing of Lorentz force. Similar results are found for permeability parameter, angle of inclination and suction parameter, also reverse results arise for remaining parameters.

- Increase in magnetic parameter, thermal Grashof number and modified Grashof number, the temperature is increased. Reverse trend arises for remaining entering parameters.

- Increase in magnetic parameter, Hall parameter Schmidt number and suction/ injection the concentration decreases and there is no effect for other parameters.

It is interesting to note that the temperature profile is decreased for $K \leq 2$ but when $K \geq 3$ then it is increased

\section{Nomenclature:}

\begin{tabular}{|ll|}
\hline MHD & Magnetohydrodynamics \\
$\mathrm{c}_{\mathrm{p}}$ & Specific heat of with constant pressure \\
$\mathrm{g}$ & Gravitational acceleration \\
$\mathrm{g}_{0}$ & Secondary Velocity \\
$\mathrm{f}^{\prime}$ & Velocity Profile \\
$\mathrm{M}$ & Magnetic parameter, \\
& $\mathrm{M}=\frac{\sigma \mathrm{B}_{0}^{2} \mathrm{x}}{\rho \mathrm{A}}$ \\
$\mathrm{m}$ & Hall parameter \\
$v$ & Kinematic viscosity \\
$\gamma$ & Inclination of the Plate \\
\hline
\end{tabular}




\begin{tabular}{|c|c|}
\hline$\eta$ & Similarity variable \\
\hline$\alpha$ & Thermal diffusivity \\
\hline$\beta$ & Thermal Expansion Coefficient \\
\hline$\beta^{*}$ & Coefficient of expansion with concentration \\
\hline Q & Density \\
\hline$\sigma$ & Fluid electrical conductivity \\
\hline$\theta$ & Dimensionless temperature \\
\hline $\mathrm{u}$ & Velocity component in $\mathrm{x}$-direction \\
\hline $\mathrm{v}$ & Velocity component in y-direction \\
\hline $\mathrm{w}$ & Secondary Velocity \\
\hline $\mathrm{T}$ & Temperature \\
\hline $\mathrm{D}$ & Thermal molecular diffusivity \\
\hline $\mathrm{F}_{\mathrm{w}}$ & Dimensionless suction velocity \\
\hline $\mathrm{C}$ & Concentration \\
\hline $\mathrm{C}_{\infty}$ & Concentration of the fluid outside the boundary layer \\
\hline $\mathrm{P}_{\mathrm{r}}$ & $\begin{array}{l}\text { Prandle number, } \\
\mathrm{P}_{\mathrm{r}}=\frac{\mu \mathrm{c}_{\mathrm{p}}}{\rho}\end{array}$ \\
\hline $\mathrm{G}_{\mathrm{r}}$ & $\begin{array}{l}\text { Local thermal Grashof number, } \\
\mathrm{G}_{\mathrm{r}}=\frac{\mathrm{g} \beta\left(\mathrm{T}_{\mathrm{w}}-\mathrm{T}_{\infty}\right) \mathrm{x}}{\mathrm{A}^{2}}\end{array}$ \\
\hline $\mathrm{G}_{\mathrm{c}}$ & $\begin{array}{l}\text { Local solutal Grashof number } \\
\mathrm{G}_{\mathrm{c}}=\frac{\mathrm{g} \beta^{*}\left(\mathrm{C}_{\mathrm{w}}-C_{\infty}\right) \mathrm{x}}{\mathrm{A}^{2}}\end{array}$ \\
\hline$E_{c}$ & $\begin{array}{l}\text { Eckert number, } \\
\mathrm{E}_{\mathrm{c}}=\frac{\mu \mathrm{A}^{2}}{\mathrm{kx}\left(\mathrm{T}_{\mathrm{w}}-T_{\infty}\right)}\end{array}$ \\
\hline $\mathrm{S}_{\mathrm{c}}$ & $\begin{array}{l}\text { Schmidt number, } \\
\mathrm{S}_{\mathrm{c}}==\frac{v}{\rho}\end{array}$ \\
\hline $\mathrm{k}^{*}$ & Permeability of the porous medium \\
\hline K & Permeability parameter \\
\hline $\mathrm{B}_{0}$ & Constant magnetic field intensity \\
\hline $\mathrm{T}_{\mathrm{w}}$ & Temperature at the Plate \\
\hline $\mathrm{T}_{\infty}$ & Temperature of the fluid outside the boundary layer \\
\hline k & Thermal conductivity \\
\hline W & Quantities at wall \\
\hline$\infty$ & Quantities at the free stream \\
\hline
\end{tabular}


Engineering International, Volume 2, No 1 (2014)

Table-1: The skin friction coefficient at the wall, for various values of

$\mathrm{M}, \mathrm{m}, \gamma, \mathrm{P}_{\mathrm{r},} \mathrm{G}_{\mathrm{r}}, \mathrm{G}_{\mathrm{c}}, \mathrm{F}_{\mathrm{w}}, \mathrm{K}$ and taking $\mathrm{S}_{\mathrm{c}}=0.22, \mathrm{E}_{\mathrm{c}}=3.0$

\begin{tabular}{|c|c|c|c|c|c|c|c|c|}
\hline $\mathbf{M}$ & m & $\mathbf{K}$ & $\gamma$ & $P_{r}$ & $\mathrm{G}_{\mathrm{c}}$ & $\mathrm{Gr}_{\mathrm{r}}$ & $\mathrm{F}_{\mathrm{w}}$ & $\mathrm{f}^{\prime \prime}(0)$ \\
\hline 1.0 & 0.2 & 1.0 & $30^{\circ}$ & 0.71 & 3.0 & 3.0 & 1.0 & 0.548509 \\
\hline 2.0 & 0.2 & 1.0 & $30^{\circ}$ & 0.71 & 3.0 & 3.0 & 1.0 & 0.037127 \\
\hline 3.0 & 0.2 & 1.0 & $30^{\circ}$ & 0.71 & 3.0 & 3.0 & 1.0 & -0.486827 \\
\hline 1.0 & 0.2 & 1.0 & $30^{\circ}$ & 0.71 & 3.0 & 3.0 & 1.0 & 0.548509 \\
\hline 1.0 & 0.6 & 1.0 & $30^{\circ}$ & 0.71 & 3.0 & 3.0 & 1.0 & 0.5921997 \\
\hline 1.0 & 0.9 & 1.0 & $30^{\circ}$ & 0.71 & 3.0 & 3.0 & 1.0 & 0.655833 \\
\hline 1.0 & 0.2 & 1.0 & $30^{\circ}$ & 0.71 & 3.0 & 3.0 & 1.0 & 0.548509 \\
\hline 1.0 & 0.2 & 2.0 & $30^{\circ}$ & 0.71 & 3.0 & 3.0 & 1.0 & -0.325895 \\
\hline 1.0 & 0.2 & 3.0 & $30^{\circ}$ & 0.71 & 3.0 & 3.0 & 1.0 & -1.210374 \\
\hline 1.0 & 0.2 & 1.0 & $30^{\circ}$ & 0.71 & 3.0 & 3.0 & 1.0 & 0.548509 \\
\hline 1.0 & 0.2 & 1.0 & $45^{0}$ & 0.71 & 3.0 & 3.0 & 1.0 & 0.128442 \\
\hline 1.0 & 0.2 & 1.0 & $60^{\circ}$ & 0.71 & 3.0 & 3.0 & 1.0 & -0.0472449 \\
\hline 1.0 & 0.2 & 1.0 & $30^{\circ}$ & 0.71 & 3.0 & 3.0 & 1.0 & 0.548509 \\
\hline 1.0 & 0.2 & 1.0 & $30^{\circ}$ & 1.0 & 3.0 & 3.0 & 1.0 & 0.553417 \\
\hline 1.0 & 0.2 & 1.0 & $30^{\circ}$ & 7.0 & 3.0 & 3.0 & 1.0 & 0.615444 \\
\hline 1.0 & 0.2 & 1.0 & $30^{\circ}$ & 1.0 & 3.0 & 3.0 & 1.0 & 0.548509 \\
\hline 1.0 & 0.2 & 1.0 & $30^{\circ}$ & 1.0 & 4.0 & 3.0 & 1.0 & 0.921111 \\
\hline 1.0 & 0.2 & 1.0 & $30^{\circ}$ & 1.0 & 5.0 & 3.0 & 1.0 & 1.267379 \\
\hline 1.0 & 0.2 & 1.0 & $30^{\circ}$ & 1.0 & 3.0 & 3.0 & 1.0 & 0.548509 \\
\hline 1.0 & 0.2 & 1.0 & $30^{\circ}$ & 1.0 & 3.0 & 4.0 & 1.0 & 0.858208 \\
\hline 1.0 & 0.2 & 1.0 & $30^{\circ}$ & 1.0 & 3.0 & 5.0 & 1.0 & 1.1217915 \\
\hline 1.0 & 0.2 & 1.0 & $30^{\circ}$ & 1.0 & 3.0 & 3.0 & -1.0 & 0.849388 \\
\hline 1.0 & 0.2 & 1.0 & $30^{\circ}$ & 1.0 & 3.0 & 3.0 & 0.0 & 0.725358 \\
\hline 1.0 & 0.2 & 1.0 & $30^{\circ}$ & 1.0 & 3.0 & 3.0 & 1.0 & 0.548509 \\
\hline
\end{tabular}

Table-2: The rate of heat transfer at the wall, for various values of $\mathrm{M}, \mathrm{m}, \gamma, \mathrm{P}_{\mathrm{r}}, \mathrm{G}_{\mathrm{r}}, \mathrm{G}_{\mathrm{c}}, \mathrm{F}_{\mathrm{w}}, \mathrm{K}$ and taking $\mathrm{S}_{\mathrm{c}}=0.22, \mathrm{E}_{\mathrm{c}}=3.0$

\begin{tabular}{|c|c|c|c|c|c|c|c|c|}
\hline $\mathbf{M}$ & $\mathbf{m}$ & $\mathbf{K}$ & $\gamma$ & $\mathbf{P r}_{\mathbf{r}}$ & $\mathbf{G}_{\mathbf{c}}$ & $\mathbf{G}_{\mathbf{r}}$ & $\mathrm{F}_{\mathbf{w}}$ & $-\theta^{\prime}(0)$ \\
\hline 1.0 & 0.2 & 1.0 & $30^{0}$ & 0.71 & 3.0 & 3.0 & 1.0 & 1.834366 \\
\hline 4.0 & 0.2 & 1.0 & $30^{0}$ & 0.71 & 3.0 & 3.0 & 1.0 & 1.771562 \\
\hline 7.0 & 0.2 & 1.0 & $30^{0}$ & 0.71 & 3.0 & 3.0 & 1.0 & 1.073092 \\
\hline 1.0 & 0.2 & 1.0 & $30^{0}$ & 0.71 & 3.0 & 3.0 & 1.0 & 1.834366 \\
\hline 1.0 & 0.2 & 1.0 & $30^{0}$ & 0.71 & 3.0 & 3.0 & 1.0 & - \\
\hline 1.0 & 0.2 & 1.0 & $30^{0}$ & 0.71 & 3.0 & 3.0 & 1.0 & - \\
\hline 1.0 & 0.2 & 1.0 & $30^{0}$ & 0.71 & 3.0 & 3.0 & 1.0 & 1.834366 \\
\hline 1.0 & 0.2 & 2.0 & $30^{0}$ & 0.71 & 3.0 & 3.0 & 1.0 & 1.897262 \\
\hline 1.0 & 0.2 & 3.0 & $30^{\circ}$ & 0.71 & 3.0 & 3.0 & 1.0 & 1.634461 \\
\hline 1.0 & 0.2 & 4.0 & $30^{\circ}$ & 0.71 & 3.0 & 3.0 & 1.0 & 1.0485202 \\
\hline 1.0 & 0.2 & 1.0 & $30^{\circ}$ & 0.71 & 3.0 & 3.0 & 1.0 & 1.834366 \\
\hline
\end{tabular}


Engineering International, Volume 2, No 1 (2014)

\begin{tabular}{|l|l|l|l|l|l|l|l|l|}
\hline 1.0 & 0.2 & 1.0 & $30^{\circ}$ & 0.71 & 3.0 & 3.0 & 1.0 & - \\
\hline 1.0 & 0.2 & 1.0 & $30^{\circ}$ & 0.71 & 3.0 & 3.0 & 1.0 & 1.834366 \\
\hline 1.0 & 0.2 & 1.0 & $30^{\circ}$ & 1.0 & 3.0 & 3.0 & 1.0 & 1.924583 \\
\hline 1.0 & 0.2 & 1.0 & $30^{\circ}$ & 7.0 & 3.0 & 3.0 & 1.0 & 4.221751 \\
\hline 1.0 & 0.2 & 1.0 & $30^{\circ}$ & 1.0 & 3.0 & 3.0 & 1.0 & 1.834366 \\
\hline 1.0 & 0.2 & 1.0 & $30^{\circ}$ & 1.0 & 4.0 & 3.0 & 1.0 & 1.786807 \\
\hline 1.0 & 0.2 & 1.0 & $30^{\circ}$ & 1.0 & 5.0 & 3.0 & 1.0 & 1.621447 \\
\hline 1.0 & 0.2 & 1.0 & $30^{\circ}$ & 1.0 & 3.0 & 3.0 & 1.0 & 1.834366 \\
\hline 1.0 & 0.2 & 1.0 & $30^{\circ}$ & 1.0 & 3.0 & 4.0 & 1.0 & 1.789751 \\
\hline 1.0 & 0.2 & 1.0 & $30^{\circ}$ & 1.0 & 3.0 & 5.0 & 1.0 & 1.713647 \\
\hline 1.0 & 0.2 & 1.0 & $30^{\circ}$ & 1.0 & 3.0 & 3.0 & -1.0 & 1.192054 \\
\hline 1.0 & 0.2 & 1.0 & $30^{\circ}$ & 1.0 & 3.0 & 3.0 & 0.0 & 1.541049 \\
\hline 1.0 & 0.2 & 1.0 & $30^{\circ}$ & 1.0 & 3.0 & 3.0 & 1.0 & 1.834366 \\
\hline
\end{tabular}

Table-3: The rate of concentration at the wall, for various values of $\mathrm{M}, \mathrm{m}, \mathrm{S}_{\mathrm{c}}, \mathrm{P}_{\mathrm{r}}, \mathrm{G}_{\mathrm{r}}, \mathrm{G}_{\mathrm{c}}, \mathrm{F}_{\mathrm{w}}, \mathrm{K}$ and taking $\gamma=30^{\circ}, \mathrm{E}_{\mathrm{c}}=3.0$

\begin{tabular}{|c|c|c|c|c|c|c|c|c|}
\hline $\mathbf{M}$ & $\mathbf{m}$ & $\mathbf{K}$ & $\mathbf{S}_{\mathbf{c}}$ & $\mathbf{P}_{\mathbf{r}}$ & $\mathbf{G}_{\mathbf{c}}$ & $\mathbf{G}_{\mathbf{r}}$ & $\mathrm{F}_{\mathbf{w}}$ & $-\varphi^{\prime}(0)$ \\
\hline 1.0 & 0.2 & 1.0 & 0.22 & 0.71 & 3.0 & 3.0 & 1.0 & 2.06509 \\
\hline 2.0 & 0.2 & 1.0 & 0.22 & 0.71 & 3.0 & 3.0 & 1.0 & 2.065207 \\
\hline 3.0 & 0.2 & 1.0 & 0.22 & 0.71 & 3.0 & 3.0 & 1.0 & 2.06531 \\
\hline 1.0 & 0.2 & 1.0 & 0.22 & 0.71 & 3.0 & 3.0 & 1.0 & 2.06509 \\
\hline 1.0 & 0.6 & 1.0 & 0.22 & 0.71 & 3.0 & 3.0 & 1.0 & 2.06508 \\
\hline 1.0 & 0.9 & 1.0 & 0.22 & 0.71 & 3.0 & 3.0 & 1.0 & 2.06505 \\
\hline 1.0 & 0.2 & 1.0 & 0.22 & 0.71 & 3.0 & 3.0 & 1.0 & 2.06509 \\
\hline 1.0 & 0.2 & 2.0 & 0.22 & 0.71 & 3.0 & 3.0 & 1.0 & 2.06509 \\
\hline 1.0 & 0.2 & 3.0 & 0.22 & 0.71 & 3.0 & 3.0 & 1.0 & 2.06509 \\
\hline 1.0 & 0.2 & 1.0 & 0.22 & 0.71 & 3.0 & 3.0 & 1.0 & 2.06509 \\
\hline 1.0 & 0.2 & 1.0 & 0.60 & 0.71 & 3.0 & 3.0 & 1.0 & 2.18052 \\
\hline 1.0 & 0.2 & 1.0 & 0.97 & 0.71 & 3.0 & 3.0 & 1.0 & 2.29651 \\
\hline 1.0 & 0.2 & 1.0 & 0.22 & 0.71 & 3.0 & 3.0 & 1.0 & 2.06509 \\
\hline 1.0 & 0.2 & 1.0 & 0.22 & 1.0 & 3.0 & 3.0 & 1.0 & 2.06509 \\
\hline 1.0 & 0.2 & 1.0 & 0.22 & 7.0 & 3.0 & 3.0 & 1.0 & 2.06509 \\
\hline 1.0 & 0.2 & 1.0 & 0.22 & 1.0 & 3.0 & 3.0 & 1.0 & 2.06509 \\
\hline 1.0 & 0.2 & 1.0 & 0.22 & 1.0 & 4.0 & 3.0 & 1.0 & 2.06499 \\
\hline 1.0 & 0.2 & 1.0 & 0.22 & 1.0 & 5.0 & 3.0 & 1.0 & 2.06493 \\
\hline 1.0 & 0.2 & 1.0 & 0.22 & 1.0 & 3.0 & 3.0 & 1.0 & 2.06509 \\
\hline 1.0 & 0.2 & 1.0 & 0.22 & 1.0 & 3.0 & 4.0 & 1.0 & 2.06501 \\
\hline 1.0 & 0.2 & 1.0 & 0.22 & 1.0 & 3.0 & 5.0 & 1.0 & 2.06493 \\
\hline 1.0 & 0.2 & 1.0 & 0.22 & 1.0 & 3.0 & 3.0 & -1.0 & 1.95473 \\
\hline 1.0 & 0.2 & 1.0 & 0.22 & 1.0 & 3.0 & 3.0 & 0.0 & 2.00941 \\
\hline 1.0 & 0.2 & 1.0 & 0.22 & 1.0 & 3.0 & 3.0 & 1.0 & 2.06509 \\
\hline
\end{tabular}




\section{REFERENCES}

Acharya,M., Dash, G. C. and Singh,L.P.199. Effect of chemical and thermal diffusion with Hall current on unsteady hydromagnetic flow near an infinite vertical porous plate, J. Phys. D: Appl. Phys. 28, 2455-2464.

Chakrabarti and A. S. Gupta.1979. Hydromagnetic Flow and Heat Transfer over a Stretching Sheet. Quarterly Journal of Mechanics and Applied Mathematics. Vol. 37, pp. 73-78.

Das, S.S. Sahoo, S.K. and Dash, G.C. 2006. Numerical solution of mass transfer effects on unsteady flow past an accelerated vertical porous plate with suction. Bull. Malays Math Science Soc. (2), $29,33-42$.

Dash, G.C. and Das, S.S.1999. Hall effect on MHD flow along an accelerated porous flat plate with mass transfer and internal heat generation. Math. Engng. Indust., 7(4), 389-404.

H. I. Andersson .1992. MHD Flow of Viscoelastic Fluid past a Stretching Surface. Acta Mechanica, Vol. 95, pp.227- 230.

Hasimoto H.1957. Boundary layer growth on a flat plate with suction or injection. J. Phys. Soc. Japan 12 6875.

Ibrahim S.Y. and Makinde O.D. 2010. Chemically reacting MHD boundary layer flow of heat and mass transfer over a moving vertical plate with suction, Scientific Research and essays Vol. 5(19), pp. 2875-2882.

Israel,C. - Cookey, Ogulu,A. and Omubo-pepple,V.B. 2003. Influence of viscous dissipation and radiation on unsteady MHD free convection flow past an infinite heated vertical plate in a porous medium with time dependent suction. Int. J. Heat Mass Transfer, 46, 2305-2311.

K. V. Prasad, D. Pal, V. Umesh and N. S. Prasanna Rao February 2010.The Effect of Variable Viscosity on MHD Viscoelastic Fluid Flow and Heat Transfer over a Stretching Sheet. Communications in Nonlinear Science and Numerical Simulation, Vol. 15, No. 2, pp. 331-344.

M. A. Seddeek. 2007. Heat and Mass Transfer on a Stretching Sheet with a Magnetic Field in a Visco-Elastic Fluid Flow through a Porous Medium with Heat Source or Sink. Computational Materials Science. Vol. 38, pp. 781-787.

M.Prasanna Lakshmi, N. Bhaskar Reddy and T. Poornima.2012. MHD Boundary Layer Flow of Heat and Mass Transfer over a Moving Vertical Plate in a Porous Medium with Suction and Viscous Dissipation. International Journal of Engineering Research and Applications (IJERA), Vol. 2, Issue 5, September- October 2012, pp.149-159.

Mishra,S,P. and Dash,G.C.1974. Free convection of non-Newtonian fluids between parallel walls. Indian J. Pure Appl. Math., 5,6-12 .

Panda, J.P., Dash, G.C. and Das, S.S. 2003 .Unsteady free convective flow and mass transfer of a rotating elasticoviscous liquid through porous media past a vertical porous plate. AMSE J. Mod.Meas.Cont. B, 72(3), 47-59.

Pop,I. and Soundalgekar, V.M(1980)."Free convection flow past an accelerated infinite place". Z. Angrew, Math. Mech.60 167-168.

Raptis,A., Singh, A.K.and Rai, K.D.1987. Finite difference analysis of unsteady free convective flow through a porous medium adjacent to a semi-infinite vertical plate, Mech. Res. Comm., 14, 9-16.

S. Abel and N. Mahesha .2008. Heat Transfer in MHD Viscoelastic Fluid Flow over a Stretching Sheet with Variable Thermal Conductivity, Non-Uniform Heat Source and Radiation. Applied Mathematical Modelling, Vol. 32, pp. 1965-1983.

S. Abel, A. Joshi and R. M. Sonth .2001. Heat Transfer in a MHD Visco-Elastic Fluid over a Stretching Surface. Journal of Applied Mathematics and Mechanics,Vol. 81, pp. 691-698.

S. Abel, P. H. Veena, K. Rajgopal and V. K. Pravin . 2004. Non-Newtonian Magneto Hydrodynamic Flow over a Stretching Surface with Heat and Mass Transfer," International Journal of Non-Linear Mechanics, Vol. 39, pp. 1067-1078. 
Satter, M.A. 1994. Free convection and mass transfer flow through a porous medium past an infinite vertical porous plate with time dependent temperature and concentration, Ind. J. Pure Appl. Math., 23, 759-766.

Sharma PR and Mishra U. 2002. Effect of mass transfer in unsteady MHD flow and heat transfer past an infinite porous vertical moving plate. Indian J. Theo. Phys, India, 50, 109-115.

Sharma, P.R. and Singh, G. 2008. Unsteady MHD free convective flow and heat transfer along a vertical porous plate with variable suction and internal heat generation.Int. J. Appl. Maths\& Mechanics, 4, 01-08.

Singh, A.K. and Dikshit, C.K.. 1988. Hydromagnetic flow past a continuously moving semi-infinite plate at large suction. Astrophys, Space Sci., 248, 249-256.

Singh, A.K. and Soundalgekar, V.M.1990. Transient free convection in cold water past an infinite vertical porous plate, Int. J. of Energy Res., 14, 413-420.

Singh, A.K..1983. Finite difference analysis of MHD free convective flow past an accelerated vertical porous plate ,Astrophys Space Sci., $94,395-400$.

Soundalgekar, V.M. 1974. Free convection effects on steady MHD flow past a vertical porous plate", J. Fluid Mech. 66, 541-551.

T. Sarpakaya.1961. Flow of Non-Newtonian Fluids in Magnetic Field. AICHE Journal, Vol. 7, pp. 324-328.

Vajravelu,K..1979. Natural convection at heated semi-infinite vertical plate with internal heat generation. Acta Mech.34 153-159.

\section{CALl fOR PAPER}

American Journal of Trade and Policy

(AJTP) is an open-access, peer-reviewed interdisciplinary journal which seeks articles from any broad theme of international trade.

AJTP features reports on current developments in international trade as well as on related policy issues. The digital online version is published by AJTP, and the hard copy (print) version is published by Asian Business Consortium (ABC). Web: www.ajtp.us
Asia Pacific Journal of Energy and Environment (APJEE) is a peer-reviewed multi-disciplinary international journal devoted to academic advanced research from the energy and environment arena. It specializes in the publication of comparative thematic issues as well as individual research articles, review essays, and book reviews. APJEE is fully and freely accessible on line. Web: www.apjee-my.weebly.com 